\title{
Dental Health in the COVID - 19 eras: A Newer Prospective
}

\author{
Bhawna Gupta ${ }^{1}$ and Manoj Gupta*2 \\ ${ }^{1}$ Sri Balaji Action Medical Institute, India \\ ${ }^{2}$ Montefiore Medical Center, USA
}

Corresponding author: Manoj Gupta, Montefiore Medical Center, USA

\begin{tabular}{|c|c|}
\hline ARTICLE INFO & ABSTRACT \\
\hline Received: 幽 October 24, 2020 & Citation: Bhawna Gupta, Manoj Gupta. Dental Health in the COVID - 19 eras: A Newer \\
\hline Published: 慧 October 29, 2020 & Prospective. Biomed J Sci \& Tech Res 31(3)-2020. BJSTR. MS.ID.005111. \\
\hline
\end{tabular}

\section{Editorial}

Oral health is an important component of good overall health and well-being. As we all know, the best way to keep our smile beautiful, in addition to cultivating good oral hygiene habits at home, is to have regular dental checkups and professional teeth cleaning twice a year. Professional cleaning will keep your gums and teeth healthy and bright, respectively. As per CDC, nationally, more than half of children ages 6 to 19 have experienced tooth decay. In NYC, more than one in three third-grade students have untreated tooth decay. So many adults in the U.S. have experienced tooth decay and nearly half of adults have gum disease. By taking simple measures, most oral health problems can be prevented. Preventing oral health problems can reduce health care expenses.

All of us, including you and as health care professionals have been watching the events very-very closely, as they have evolved over the past 6 months regarding the coronavirus pandemic. Symptoms of coronavirus are reported as flu-like, with varying degrees of severity. While we do not know everything about this virus to date, individuals who are elderly and/or immunocompromised appear to be the most at risk of a severe infection. COVID 19 pandemic has instigated a fear of catching the corona virus infection in the general population. Their fears are genuine, but it has led to delay in seeking medical attention for routine medical and dental problems including routine prophylactic dental cleaning. Some of the outpatient clinics and dental offices have suspended all scheduled elective treatments and handling only urgent dental needs and emergencies as they may arise. Standard universal precautions help protect every patient and despite the proper use of PPE (Personal protective equipment) the risk of contracting the deadly corona virus infection is not zero. Even now, when the offices are opening, and the local government has cleared the dental offices to restart scheduling some of the outpatient visits, people are hesitant to come in close contact with the health care officials for routine care. Over the last few weeks, so many people have missed/cancelled their routine dental office visits. The health care offices are raising their standards beyond the previously defined typical protocol during this time. As you probably know, the dull ache underneath that tooth which will not subside on its own may be a symptom of tooth infection, gingivitis, or bad dental caries. The uncomfortable sensitivity to hot or cold food or drink which is getting worse as days are passing and the fear of the current coronavirus [1] pandemic, many Americans are wrestling with a crucial question, is my dental problem urgent enough to go to dental office.

Based on American Dental Association [2], the following qualifies as a Dental Emergency. Broadly, a dental emergency is any oral-facial issue, including facial trauma, that is extremely time sensitive - that is, any issue affecting your mouth or facial bones that'll become much worse if you don't act soon. The things that make a dental issue an emergency are elevated pain and increased vulnerability including but not limited to severe unrelenting pain, severe tooth infection [3]. Call your dentist to get guidance on what you can do at home to keep your dental health safe and maintain that healthy smile. If your issues are not urgent, the best thing you can do; to maintain your pearly white beautiful smile is to brush your teeth twice daily with your preferred regular over the counter paste. Daily flossing and rinsing with mouthwash at least once daily 
have been recommended to maintain good oral hygiene. Closely follow CDC's Infection Control guidelines to minimize the risk of catching Covid-19 infection. These measures include increasing the frequency of hand hygiene, PPE and eye protection. To ensure health and safety for everyone please visit all dental offices with full precautions and PPE. PS: This content does not constitute medical advice. Talk with your primary care physician and your dentist about your personal risks to the Covid-19 outbreak to inform your decision of whether you are healthy enough to visit your dental office.

\section{ISSN: 2574-1241}

DOI: 10.26717/BJSTR.2020.31.005111

Manoj Gupta. Biomed J Sci \& Tech Res

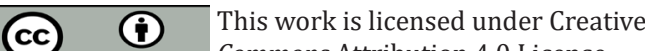

Submission Link: https://biomedres.us/submit-manuscript.php

\section{References}

1. (2020) Health Care Workers. Infection Control Guidance for Healthcare Professionals about Coronavirus (COVID-19). Centres for Disease control \& Prevention.

2. (2020) What Constitutes a Dental Emergency? ADA.

3. Kimber Solana (2020) Emergency Vs Non-Emergency Dental Procedures. ADA News.

$\begin{array}{ll}\text { BIOMEDICAL } & \text { Assets of Publishing with us } \\ \text { RESEARCHES } & \text { - Global archiving of articles } \\ \text { - Immediate, unrestricted online access }\end{array}$

